\title{
Simulation analysis of Series Cascade control Structure and anti- reset windup technique for a jacketed CSTR
}

\author{
S.Sundari ${ }^{1}$, Alamelu Nachiappan ${ }^{2}$ \\ ${ }^{I}$ (EEE Department, / Pondicherry Engineering College,India) \\ ${ }^{2}$ (EEE Department, / Rajiv Gandhi college of Engineering\&Technology ,India)
}

\begin{abstract}
A method for PID controller tuning based on process models for series cascaded control systems using anti-reset windup technique is proposed in this paper. Closed loop response is obtained using auto tuning of PID controller. This method can be applied to any closed loop stable processes. Closed loop responses of series cascade control loops tuned by the proposed anti-reset windup technique method are compared with the existing cascade control system. Simulation results on nonlinear stable continuous stirred tank reactors is presented to show the efficiency of the proposed controller using anti-reset windup technique.
\end{abstract}

Keywords: Anti-reset windup technique, CSTR, modelling, Jacket Temperature, PID controller, series cascade structure.

\section{Introduction}

Cascade control is one of the most successful methods for enhancing single-loop control performance particularly when the disturbances are associated with the manipulated variable or when the final control element exhibits nonlinear behaviour. It is one of the most popular complex control structures that can be found in the process industries implemented in order to improve the disturbance rejection properties of the controlled system[1] [2]. In [3] a relay-feedback based auto tuning method has been used. The procedure still needs of a sequential application of the usual relay based auto tuning approach consuming. Other results provide tuning rules for the primary and secondary controller [4] [5] or suggest alternative control structures based on a modification of the conventional cascade configuration [6]. When the controller is optimally tuned for setpoint response, the load-disturbance performance can be very poor [7]. The integral state prediction (ISP) method is used in [8].The system involves two steps for tuning cascade control systems: first the secondary controller is tuned on the basis of the dynamic model of the inner process. Then, the primary controller is tuned on the basis of the dynamic model of the outer process including the secondary loop. Therefore, if the secondary controller is retuned for some reason, an additional identification step is essential for retuning the primary controller. The phenomenon of reset windup occurs when a controller with integral action operates with the manipulated variable. When the manipulated variable hits the constraint the integral time in a PID controller continues to accumulate the error and overshoot will occur. The contents of the paper are arranged as follows. Section 1 provides the introduction to the temperature control of CSTR using PID. Section 2 deals with the modelling of CSTR and obtaining transfer function for jacket temperature and coolant flow rate. Section 3 deals with analysis of the series cascade structure and auto tuning of controllers. Section 4 explains the anti reset windup protection. Section 5 illustrates the implementation of anti reset windup technique for the controllers using simulink. Section 6 deals with conclusions.

\section{Modeling Of Cstr}

The examined reactor has real background and graphical diagram of the CSTR reactor as shown in Figure 1. The mathematical model of this reactor comes from balances inside the reactor. Notice that a jacket surrounding the reactor also has feed and exit streams. The jacket is assumed to be perfectly mixed and at lower temperature than the reactor. Energy passes through the reactor walls into jacket removing the heat generated by reaction. The control objective is to keep the temperature of the reacting mixture $\mathrm{T}$, constant at desired value. The only

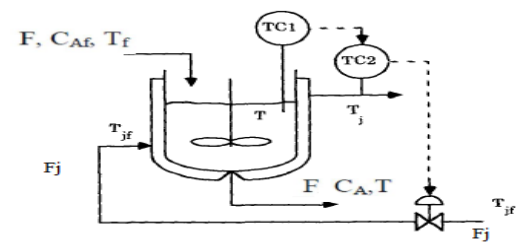

Fig1.Continuous stirred tank reactor with cooling jacket 
manipulated variable is the coolant flow rate $\mathrm{F}_{\mathrm{j}}$

\subsection{Steady State Solution}

The steady state solution is obtained when, $\frac{d C_{A}}{d t}=0 \quad \frac{d T}{d t}=0 \quad \frac{d T_{j}}{d t}=0$

fl $\left(\mathrm{C}_{\mathrm{A}}, \mathrm{T}, \mathrm{T}_{\mathrm{j}}\right)=\frac{d C_{A}}{d t}=0=F / V\left(C_{A F}-C_{A}\right)-K_{0} \exp ^{(-E / R T)} C_{A}$

$\mathrm{f} 2\left(\mathrm{C}_{\mathrm{A}}, \mathrm{T}, \mathrm{T}_{\mathrm{j}}\right)=\frac{d T}{d t}=0=\frac{F}{V}\left(T_{f}-T\right)+\left(\frac{-\Delta H}{\rho C_{P}}\right) K_{0} \exp ^{(-E / R T)} C_{A}-\frac{U A}{V \rho C_{p}}\left(T-T_{j}\right)$

$\mathrm{f} 3\left(\mathrm{C}_{\mathrm{A}}, \mathrm{T}, \mathrm{Tj}\right)=\frac{d T_{j}}{d t}=0=\frac{F_{j}}{V_{j}}\left(T_{J F}-T_{j}\right)+U A \frac{U A\left(T-T_{j}\right)}{V_{j} \rho_{j} C_{p_{j}}}$

Where $-\Delta \mathrm{H}$ is the heat of reaction, $\mathrm{U}$ is the heat transfer coefficient, $\mathrm{A}$ is the heat transfer area, $\mathrm{T}$ is the reactor temperature, and $\mathrm{T}_{\mathrm{j}}$ is the coolant temperature in the jacket. $\mathrm{C}_{\mathrm{Af}}$ is the concentration of $\mathrm{A}$ in feed. $\mathrm{Vj}$ is the volume of the jacket.

Table 1: Reactor Parameter's value

\begin{tabular}{|l|c|}
\hline Reactor parameters & Values \\
\hline $\mathrm{F} / \mathrm{V}, \mathrm{hr}-1$ & 1 \\
\hline $\mathrm{Ko}, \mathrm{hr}-1$ & $16.96^{*} 10^{12}$ \\
\hline$(-\Delta \mathrm{H}), \mathrm{kcal} / \mathrm{kmol}$ & 5960 \\
\hline $\mathrm{E}, \mathrm{kcal} / \mathrm{kmol}$ & 11843 \\
\hline$\Delta \mathrm{Cp}, \mathrm{kcal} / \mathrm{m}^{{ }^{\circ}}{ }^{\circ} \mathrm{C}$ & 500 \\
\hline $\mathrm{T}_{\mathrm{if}}{ }^{\prime} \mathrm{c} \mathrm{Caf}, \mathrm{kmol} / \mathrm{m} 3$ & 25 \\
\hline $\mathrm{UA} / \mathrm{V}, \mathrm{kcal} / \mathrm{m} 3{ }^{\prime} \mathrm{c} . \mathrm{hr}$ & 150 \\
\hline $\mathrm{Tj}{ }^{\circ} \mathrm{C}$ & 25 \\
\hline
\end{tabular}

\subsection{LINEARIZATION}

The goal of the linearization procedure is to find a model with the form

$\dot{X}=\mathrm{Ax}+\mathrm{Bu}$

$\mathrm{y}=\mathrm{Cx}+\mathrm{Du}$

Where the states, inputs and output are in deviation variable. Using the parameters given in above table we can find the state space model and transfer function for PID controller design. Hence the transfer function for PID control is given by equation 6 .

$G_{P 1}=\frac{1.458 \mathrm{~S}+11.65}{\mathrm{~S}^{2}+3.434 \mathrm{~S}+3.557}$

Using all reactor parameter's value state space model for cascade system is determined.

$\mathrm{A}=\left[\begin{array}{ccc}-7.999 & -0.013674 & 0 \\ 2922.9 & 4.5564 & 1.4582 \\ 0 & 4.7482 & 5.8977\end{array}\right]$

$\mathrm{B}=\left[\begin{array}{c}0 \\ 0 \\ -3.2558\end{array}\right]$

$\mathrm{C}=\left[\begin{array}{lll}0 & 0 & 1 \\ 0 & 1 & 0\end{array}\right]$

$\mathrm{D}=\left[\begin{array}{l}0 \\ 0\end{array}\right]$

$\mathrm{G}_{\mathrm{P} 1}$ is the transfer function between $(\mathrm{T} / \mathrm{Tj})$

$\mathrm{G}_{\mathrm{P} 1}=\frac{4.7476 \mathrm{~S}+37.9377}{3.2558 \mathrm{~S}^{2}+11.1820 \mathrm{~S}+11.260}$

$\mathrm{G}_{\mathrm{p} 2}$ is the transfer function between $(\mathrm{Tj} / \mathrm{Fj})$ 
$\mathrm{G}_{\mathrm{P} 2}=\frac{-3.2558 s^{2}-11.182 s-11.2606}{s^{3}+9.3322 s^{2}+16.7904 s-34.9297}$

The feed stream concentration is $0.132 \mathrm{lbmol} / \mathrm{ft}$ and an $50 \%$ conversion of propylene oxide has been determined to be reasonable. Since $50 \%$ of propylene oxide is converted to propylene glycol, the propylene glycol concentration is $0.066 \mathrm{lb} \mathrm{mol} / \mathrm{ft} 3$. In this process, it is seen that the process has inverse response with overshoot. To overcome this problem and to obtain the desired response, we are using series cascade control. The desired parameters for the PID controller are the proportional gain $\left(\mathrm{K}_{\mathrm{P}}\right)$ integral gain $\left(\mathrm{K}_{\mathrm{I}}\right)$ and the differential gain $\left(\mathrm{K}_{\mathrm{D}}\right)$ can be calculated by the automatic PID tuning method in Matlab software.

\section{Cascade Structures And Controller Designs}

Cascade control has two objectives. The first is to suppress the effect of disturbances on the primary process output via the action of a secondary or inner control loop around a secondary process measurement. The second is to reduce the sensitivity of the primary process variable to gain variations of the part of the process in the inner control loop.Figure 2 shows the conventional cascade control system .Consider a process consisting of two parts process 1 and process 2.Process 1 output has to be controlled. For the cstr shown in figure 1,process I is the reaction in the tank and the controller output is the temperature T. Process II is the jacket and its output is $\mathrm{Tj}$ which affects the process I and consequently $\mathrm{T}$

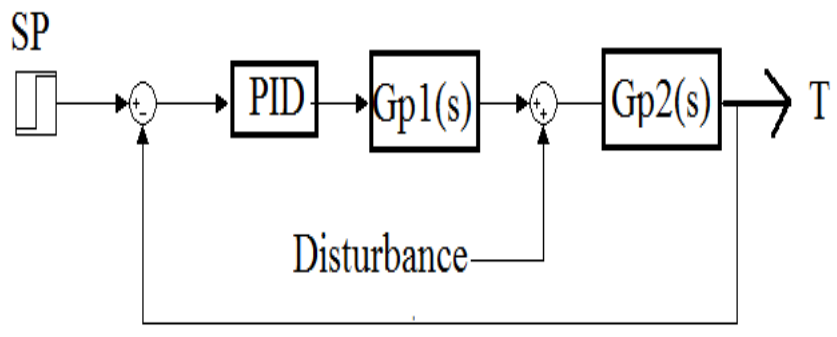

Fig 2: Block diagram representation of conventional feedback control system

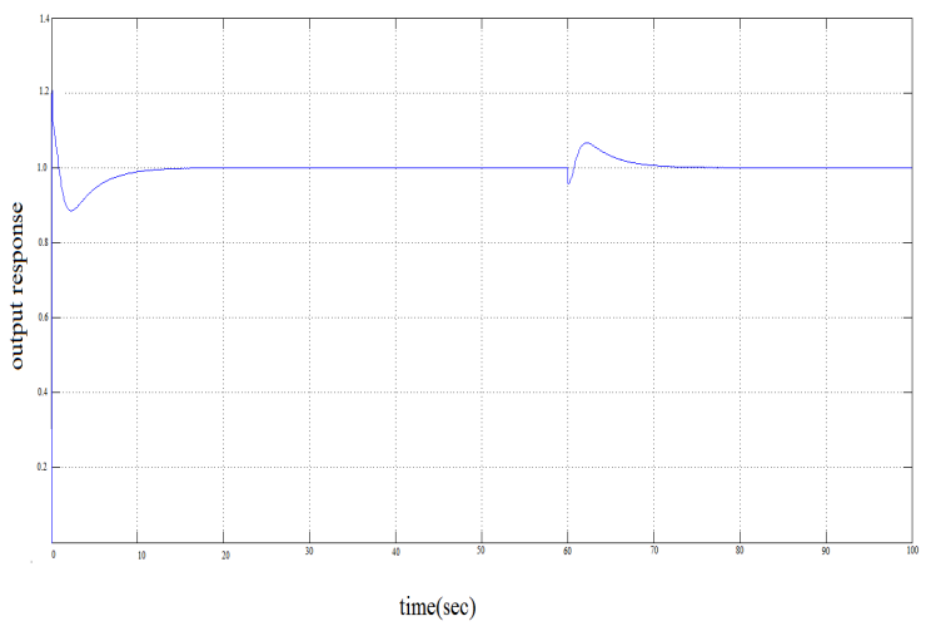

Fig 3: Step Output response of single loop conventional control system

Fig 4 shows the series cascade control system and its step output response is shown in figure 5. There are two control loops using two different measurements $T$ and $T_{j}$ but sharing a common manipulated variable $F_{j}$. In this strategy the reactor temperature controller is the primary controller while the jacket temperature controller is the secondary controller. This is effective because the jacket temperature dynamics are normally significantly faster than the reactor temperature dynamics.An inner loop disturbance such as jacket feed temperature will be felt by the jacket temperature before it has a significant effect on the reactor temperature. The inner loop controller then adjusts the manipulated variable. The jacket temperature controller manipulates the jacket flow rate. 


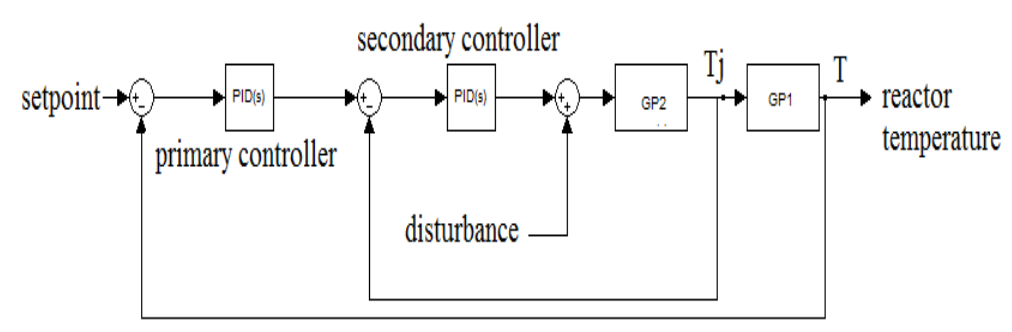

Fig:4 Block diagram representation of series cascade control system

Primary and secondary controllers are tuned for the processes I and II. Table 2 shows the tuned parameter values of primary and secondary processes.

Table 2: Tuned parameters for process I and process II

\begin{tabular}{|l|l|l|l|l|}
\hline Parameter/type & Rise time(sec) & Settling time(sec) & \% overshoot & Peak time(sec) \\
\hline Process I & 0.695 & 2.08 & 9.75 & 1.1 \\
\hline Process II & 0.0813 & 1.69 & 10.4 & 1.1 \\
\hline
\end{tabular}

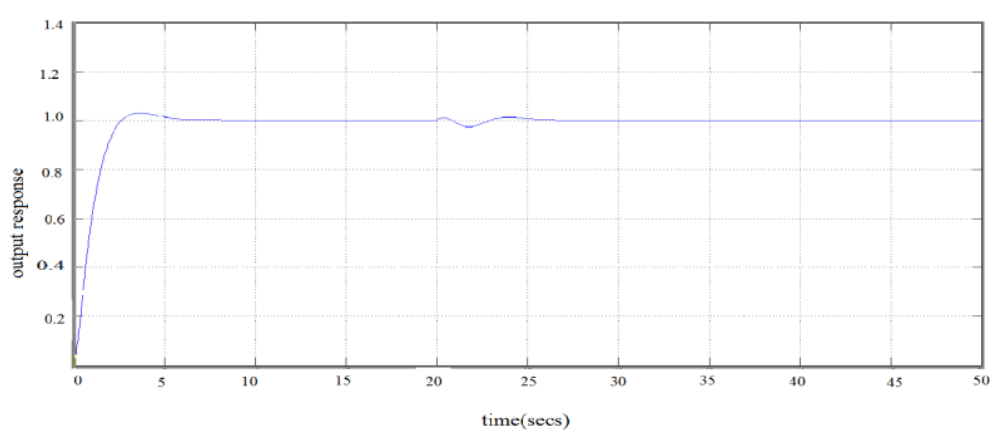

Fig 5: Step input representation of series cascade control system

\section{Anti Reset Windup Protection}

Saturation problems can arise when both primary and secondary controllers have automatic reset. The need for anti-reset windup is much greater for cascade designs since once the secondary loop is saturated, the primary controller will also saturate. When putting a cascade system into automatic operation the secondary controller must be first transferred to automatic. Primary and secondary controllers are tuned for the processes I and II.

\section{Illustration Of Anti-Reset Windup Compensation}

Reset windup is problematic in cascade control systems, particularly when batch processes are involved. The outer loop of a cascade strategy is normally tuned for much slower dynamics than is the inner loop. If the inner loop performs more slowly than expected due to constraints on the manipulated input, then the performance of the outer loop may suffer, so external reset windup protection is provided. Simulation is performed with anti windup on the secondary controller. There is still some windup involved causing overshoot of the primary process output shown in figure 6 .

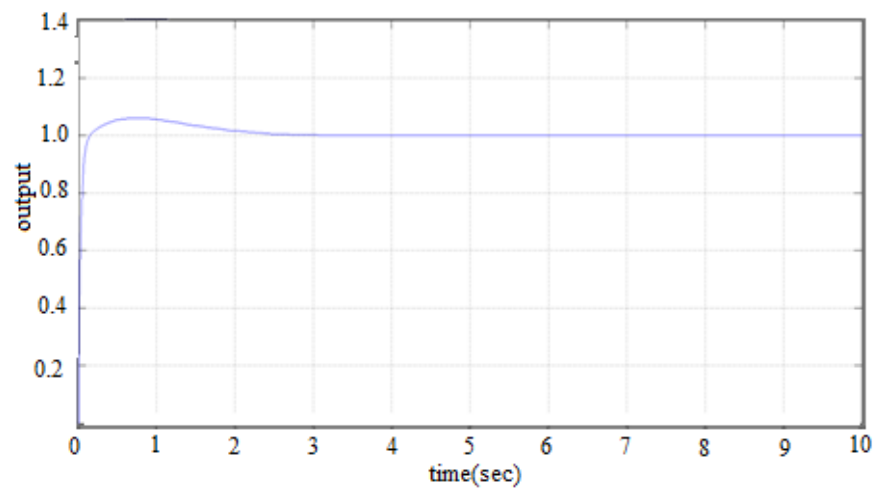


Fig 6: Step Output response of secondary controller

This is because the output of primary controller is the set point for the secondary controller. The secondary controller does not track its set point because of the saturation of the manipulated input. Improved performance can be obtained using an external input to the primary controller. Here the jacket temperature is compared with the jacket temperature set point .If the jacket temperature is not equal to its set point, some of the integral action will be removed by corrective feedback action. The improved cascade control with anti windup on the secondary loop shown in figure 7 and external resetting anti wind up on the primary loop shown in figure 8 has improved performance. The step output responses for the primary and secondary processes are shown in figures $10 \& 11$ respectively. Simulink block diagram is shown in figure 9

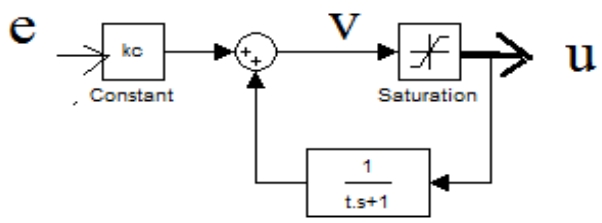

Fig 7:Anti-wind up strategy using first order feedback for the secondary loop

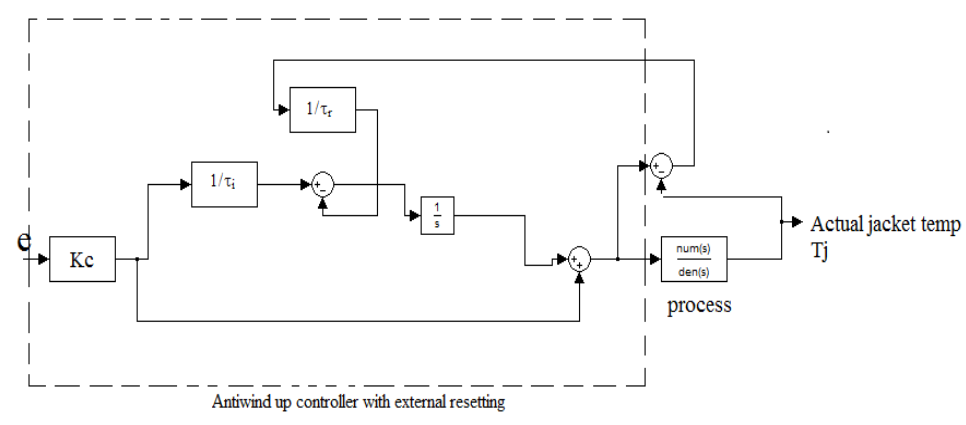

Fig 8 :Reactor temperature controller with external variable reset

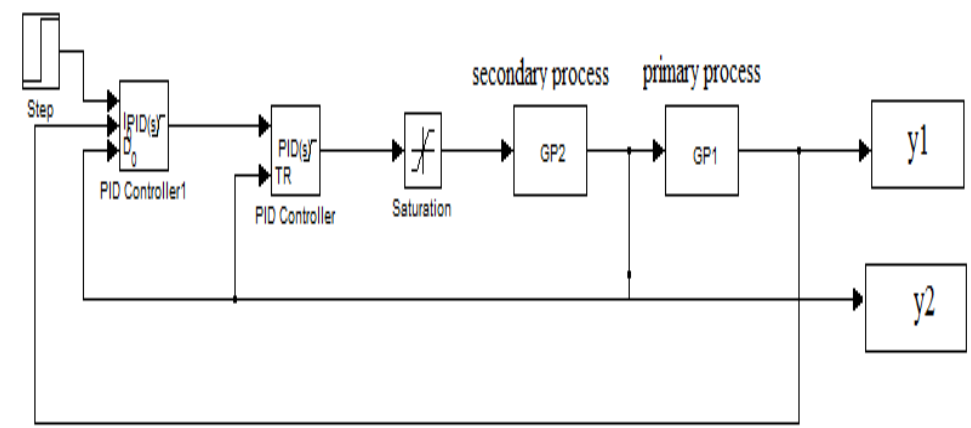

Fig 9:Cascade control simulation using anti reset windup technique on both the controllers 


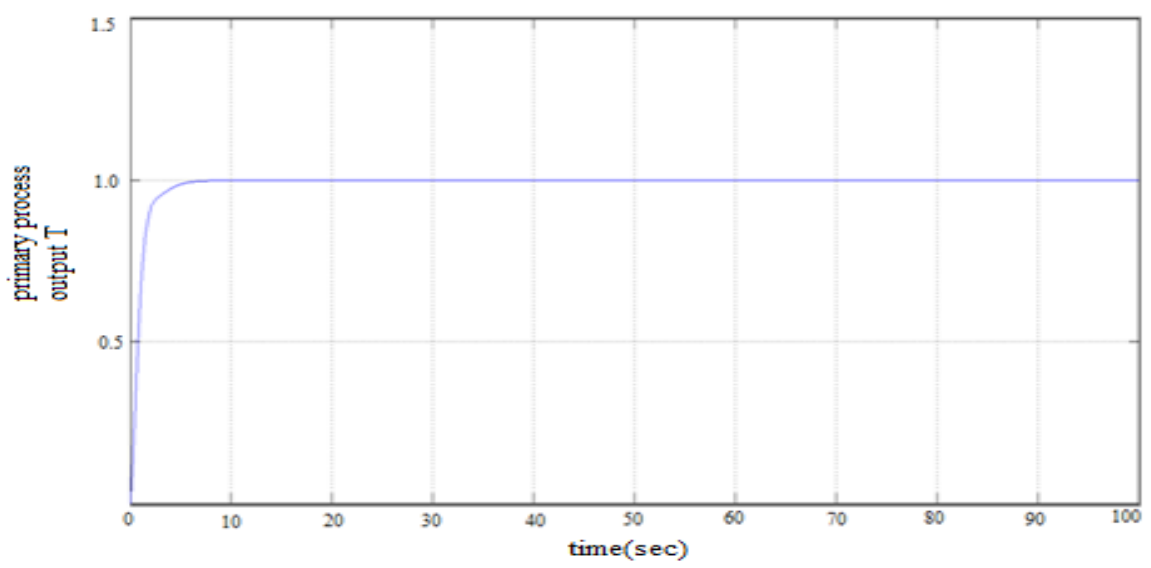

Fig 10: Step Output response of primary process output

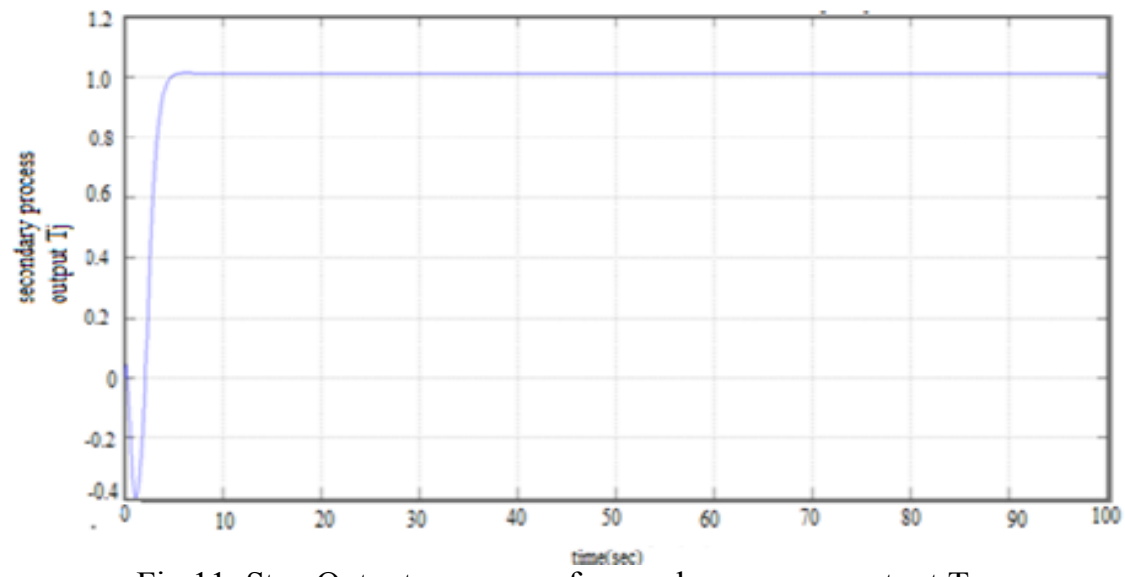

Fig 11: Step Output response of secondary process output $T_{j}$

\section{Conclusion}

Anti-reset windup for the outer loop is implemented by stopping integration when the control effort saturates in order to use the calculated integral time constant. If the anti-reset windup for the outer loop is implemented via a lag around the inner loop, then the lag time constant is not necessarily the same as the computed integral time constant. Outer loop set point tracking and disturbance rejection is generally better than that achievable with a single-loop control system because the inner loop serves to reduce the apparent gain uncertainty of the inner loop process. Simulation results show that the responses with anti -wind up has no overshoot and less settling time.

\section{Nomenclature}

\begin{tabular}{|c|c|}
\hline Notation & Description \\
\hline $\mathrm{F}_{\mathrm{j}}$ & Jacket Feed flow rate \\
\hline $\mathrm{V}$ & Reactor volume \\
\hline $\mathrm{K}_{0}$ & Acaction rate coefficient \\
\hline $\mathrm{E}_{\mathrm{a}}$ & Ideal gas constant \\
\hline $\mathrm{R}$ & Heat of reaction \\
\hline$-\Delta \mathrm{H}$ & Concentration of A in feed \\
\hline $\mathrm{C}_{\mathrm{Af}}$ & Reactor temperature \\
\hline $\mathrm{T}$ & Density \\
\hline$\rho$ & Heat capacity of solution \\
\hline $\mathrm{Cp}$ & \\
\hline
\end{tabular}




\section{References}

[1] DaleE.Seborg,ThomasF.Edgar and Duncan A.Melli champ, Process Dynamics and Control, John Wiley and Sons, 2004

[2] C. C. Hang, A. P. Loh, and V. U. Vasnani, "Relay feedback auto tuning of cascadecontrollers,"IEEE Transactions on Control Systems Technology, vol. 2, 1994. Yongho Lee and Sun won Park, "PID controller tuning to obtain desired closed loop responses for cascade control systems," Ind. Eng. Chem. Res., vol. 37, pp. 1859-1865, 1998. K. K. Tan, T. H. Lee, and R. Ferdous, "Simultaneous online automatic tuning of cascade control for open loop stable processes," ISA Transactions, vol. 39, pp. 233-242, 2000, O.Arrieta and R.Vilanova, "Performance degradation analysis of Optimal PID settings and Servo/Regulation tradeoff tuning," CSC07, Conference on Systems and Control,

[6] Kaya, N. Tan, and D. P. Atherton, "Improved cascade control structure for enhanced performance, "vol. 17, pp. 3U" 16, 2007

[7] R. Vilanova, O. Arrieta "Balanced PID Tuning Application to Series Cascade Control Systems," International Conference on Computers Comunications and Control, Felix-Spa, Romania, 15-17 May, 2008H.

[8] B. Shin, S. Lee, J. M. Park, and H. S. Shin, "Anti- windup PID controller," Korea Patent, 2010- 014689 , Feb. 18, 2010. 